NASA/TM-2000-210341

AIAA-2000-2953

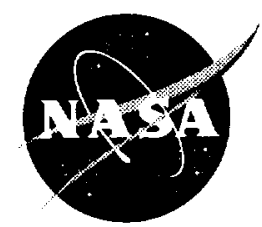

\title{
Simulation of the Interaction Between Flywheel Energy Storage and Battery Energy Storage on the International Space Station
}

Long V. Truong, Frederic J. Wolff, and Narayan V. Dravid

Glenn Research Center, Cleveland, Ohio

Ponlee Li

MP International, San Jose, California

Prepared for the

35th Intersociety Energy Conversion Engineering Conference sponsored by the American Institute of Aeronautics and Astronautics

Las Vegas, Nevada, July 24-28, 2000

National Aeronautics and

Space Administration

Glenn Research Center 
This report is a formal draft or working paper, intended to solicit comments and ideas from a technical peer group.

This report contains preliminary findings, subject to revision as analysis proceeds.

Trade names or manufacturers' names are used in this report for identification only. This usage does not constitute an official endorsement, either expressed or implied, by the National Aeronautics and Space Administration.

This report is a preprint of a paper intended for presentation at a conference. Because of changes that may be made before formal publication, this preprint is made available with the understanding that it will not be cited or reproduced without the permission of the author.

Available from

NASA Center for Aerospace Information 7121 Standard Drive

Hanover, MD 21076

Price Code: A03
National Technical Information Service 5285 Port Royal Road Springfield, VA 22100 Price Code: A03 


\title{
SIMULATION OF THE INTERACTION BETWEEN FLYWHEEL ENERGY STORAGE AND BATTERY ENERGY STORAGE ON THE INTERNATIONAL SPACE STATION
}

\author{
Long V. Truong, Frederic J. Wolff, and Narayan V. Dravid \\ National Aeronautics and Space Administration \\ Glenn Research Center \\ Cleveland, $\mathrm{OH}$ \\ Ponlee Li \\ MP International \\ San Jose, CA
}

\begin{abstract}
$\underline{\text { ABSTRACT }}$
Replacement of one module of the battery charge discharge unit (BCDU) of the International Space Station (ISS) by a flywheel energy storage unit (FESU) is under consideration. Integration of these two dissimilar systems is likely to surface difficulties in areas of system stability and fault protection. Other issues that need to be addressed include flywheel charge and discharge profiles and their effect on the ISS power system as well as filter sizing for power Ability purposes. This paper describes a SABER based simulation to study these issues.
\end{abstract}

\section{INTRODUCTION}

Flywheel development in recent years makes the FESU a potential weight saving alternative to nickel-hydrogen battery systems of the ISS [1]. However, in a large-scale power system distribution such as ISS, the replacement of BCDU and battery module by a FESU poses an uncertainty in the system interaction and system stability. Therefore, the stability issues have to be thoroughly investigated before the replacement can take place. System modeling has been initiated to explore specific issues with respect to applicability, stability, system interaction, and the status of development.

The modeling process is to build and review the models of BCDU, FESU, and associated functional photovoltaic (PV) subsystem based on the latest ISS schematics and flight hardware [2].

Copyright (c) 2000 by the American Institute of Aeronautics and Astronautics Inc. No copyright is asserted in the United States under Title 17, U.S. Code. The U.S. Govemment has a royalty-free license to exercise all rights under the copyright claimed herein for Governmental Purposes. All other rights are reserved by the copyright owner.
Since the FESU hardware is still in the development stage, the system topology of FESU proposed in this paper [3] is within the scope of FESU general guideline [4]. The FESU is designed to match the dynamics performance of the BCDU/battery assembly and the mode of operation can therefore be summarize as follows:

1. Charge Mode: The flywheel control spins up the flywheel by drawing energy from the PV subsystem primary power bus. The maximum speed of the flywheel is limited by the flywheel control.

2. Charge Reduction and Discharge Modes: The flywheel control responds to load demands to regulate the primary power bus. The flywheel spins down until it reaches an equivalent depth of discharge (DOD) of $75 \%$.

The three modes of operation, i.e., charge mode, charge reduction mode and discharge mode, have been evaluated in small-signal simulations to assess the stability issues.

\section{SYSTEM OVERVIEW}

Figure 1 shows the interconnections of the PV subsystem, which consists of solar array (SA), sequential shunt unit (SSU), battery (BAT), two BCDUs and one FESU connecting in parallel. As shown in Figure 1, the SSU output, each of the two BCDUs, and FESU are connected to the primary source bus via the direct current switching unit (DCSU). The SSU provides voltage-regulated power to the primary source bus during insolation periods. In the same insolation period, batteries are charged from the primary source bus via BCDUs, and the flywheel control spins the flywheel up to the maximum speed. During the eclipse periods, batteries and FESU are discharged to provide voltage-regulated power to the primary source bus. 
The BCDU uses the bilateral converter module to perform the functions required by $B C D U$ specification $\mathrm{RC} 1807$ [5]. Figure 2 shows the functional schematic of BCDU. In Figure 2, bilateral switches are used for bi-direction current flow, which is determined by the modes of operation. When the charge mode is in place, the buck topology is applied. While in the discharge/charge reduction mode, the boost topology is used. An average current mode control [6] has been implemented in the BCDU control circuit. In the discharge/charge reduction mode, voltage loop error amplifier (E/A) and inner current loop E/A form the control loop of BCDU. While in the charge mode, the outer current loop $\mathrm{E} / \mathrm{A}$ and inner current loop $\mathrm{E} / \mathrm{A}$, form the control loop of BCDU. The parallel circuitry in Figure 2 controls error signal flow to and from other BCDUs. The mode detection switch in the parallel circuitry is closed in the discharge/charge reduction mode to transmit error signal to other BCDUs. On the contrary, in the charge mode, the mode detection switch is open to block the error signal transmitting, therefore, each BCDU can regulate its own charge current. Since the FESU is a replacement of the BAT/BCDU module, the functional topology and system set points should be compatible with the BCDU operation.

\section{BCDU OPERATIONAL MODES AND CHARACTERISTICS}

The BCDU in discharge mode can provide up to 6.6 $\mathrm{kW}$ average or $9 \mathrm{~kW}$ peak power to the primary source bus. Voltage at battery terminal in discharge mode can range from 76 to $120 \mathrm{Vdc}$. The primary source bus voltage generated by BCDU can range from 130 to 180 $\mathrm{Vdc}$ as determined by the Local Data Interface (LDI) setpoint. While in the charge mode, $B C D U$ is powered by SSU to deliver 1 to $95 \mathrm{~A}$ of charge current to the battery as defined by LDI setpoint. Battery voltage can vary from 66 to $126 \mathrm{Vdc}$ as the SSU voltage is within the range of 130 to $180 \mathrm{Vdc}$. The function of BCDU in charge reduction mode is to regulate the primary source bus when the solar array is capable of supplying enough current to meet the load requirement of primary source bus, but not sufficient current left to supply the preset battery charge current. In this mode, BCDU starts to regulate the primary source bus voltage by reducing the charge current to be equal to $\left(I_{S A}-I_{\text {load }}\right)$ as seen from Figure 1. From the simulation of BCDU and SSU, it can be noted that the SSU will unshunt all the solar strings in the charge reduction mode. The same operation topology can be applied to discharge mode except that the $I_{\text {charge }}$ of Figure 1 will have the opposite direction of current flow.
By using the nomenclature of Figure 1, the three modes of BCDU operation can therefore be summarized as follows

1. Charge Mode

$\sum \mathrm{I}_{\text {charge }}=\mathrm{I}_{\mathrm{SA}}-\mathrm{I}_{\mathrm{load}}$

and

$\mathrm{I}_{\mathrm{SA}}-\mathrm{I}_{\text {load }}>0$

- SA \& SSU provide and regulate bus power and voltage

- BCDU conditions battery charge current

2. Charge Reduction Mode

$$
\begin{aligned}
& \sum \mathrm{I}_{\text {charge }} @ \text { schedule }>\mathrm{I}_{\mathrm{SA}}-\mathrm{I}_{\text {load }} \\
& \sum_{\mathrm{I}_{\text {charge }} @ \text { charge reduction }}=\mathrm{I}_{\mathrm{SA}}-\mathrm{I}_{\text {load }} \\
& \text { and } \\
& \mathrm{I}_{\mathrm{SA}}-\mathrm{I}_{\text {load }}>0
\end{aligned}
$$

- SSU unshunts all solar strings

- $\mathrm{BCDU}$ regulates the bus voltage

3. Discharge Mode

$$
\begin{aligned}
& \sum_{I_{\text {charge }} @ \text { discharge }}=I_{S A}-I_{\text {load }} \\
& \text { and } \\
& I_{S A}-I_{\text {load }}<0 \\
& \text { - } \quad \text { SSU unshunts all solar strings } \\
& \text { - BCDU regulates the bus voltage }
\end{aligned}
$$

Fully understanding of the BCDU function is critical in developing the control of FESU.

\section{FESU BLOCK}

Figure 3 shows the block diagram of the FESU controller model. The controller provides a smooth rotation of the FESU motor in response to a step change of the motor speed command. Accordingly, the controller will have to meet the operation requirements and limits of the rotation speed, rotation acceleration, the torque ripple of the motor, and the specification of BCDU.

In Figure 3, the primary components are voltage/current regulator, 3-phase power bridge (inverter), 3-phase brushtess motor, flywheel and the associated electronics 
control unit. The current/voltage regulator regulates the charge current feeding into the FESU in sunlight mode and the primary bus voltage with respect to the discharge mode. The inverter receives the regulated current from the current regulator and splits the current into a set of three phase motor currents. In the charge mode, the balanced three phase sinusoidal motor currents will then provide the proper commutation to the three phase brushless motor. The current regulator is controlled by a digital PID algorithm in order to reduce the steady state error and step response overshoot. The resulted PID command is used as a control reference of the current regulator. The inverter is controlled by a sine wave commutation look-up table to provide the balanced three phase sinusoidal current to the three phase brushless motor. The commutation thing of the sine wave commutation look up table is established by sensing the shaft position of the motor.

\section{SYSTEM INTERACTION}

Figure 4 shows the top-level model schematic of ISS primary power systems with one BCDU being replaced by FESU. Two BCDUs and one FESU are in parallel with the PV array/SSU to provide power to the two DCto-DC converter units (DDCUs) through the Direct Current Switching Unit (DCSU). Interaction of the FESU with the rest of the primary systems can be assessed by comparing the source impedance Zs with load impedance $Z_{\mathrm{L}}$ at the interface of FESU as indicated at point $X$ of Figure 1. In discharge mode and with an operating condition of Vbus $=173$ volts and Pload $=$ $12 \mathrm{~kW}$, the Bode plot in Figure 5 displays a significant overlapping between $\mathrm{Zs}$ and $\mathrm{Z}_{\mathrm{L}}$. The degree of system stability at this operating condition needs to be further investigated by studying the minor loop gain. The minor loop gain, $\mathrm{Tm}$, which is defined as $\mathrm{Tm}=\mathrm{Zs} / \mathrm{Z}_{\mathrm{L}}$, gives indication of the degree of system stability. To assure overall system stability, the Nyquist plot of Tm must not encircle the $(-1,0)$ point in the complex plane and always gives a phase margin greater than 30 degrees [7]. When Figure 5 is converted to Nyquist plot, it provides a phase margin of 56 degrees as indicated in Figure 6.

Table 1 and Table 2 summarize the simulation results of small signal stability analyses for both discharge and charge mode operations at FESU interface. The operations are stable with a minimum crossover phase margin of 56 degrees for the cases simulated.
Table 1: Discharge Mode

$\begin{array}{lll}\begin{array}{l}\text { Primary } \\ \text { Bus } \\ \text { (Volt) }\end{array} & \begin{array}{l}\text { Loads } \\ (\mathrm{kW})\end{array} & \begin{array}{l}\text { Z Crossover } \\ \text { Phase Margin (PM) } \\ \text { (degree) }\end{array} \\ 130 & 1.6 & 72 \\ 130 & 12 & 61 \\ 173 & 1.6 & 65 \\ 173 & 12 & 56 \\ 178 & 12 & 56\end{array}$

Table 2: Charge Mode

$\begin{array}{llll}\begin{array}{c}\text { Primary } \\ \text { Bus } \\ \text { (Volt) }\end{array} & \begin{array}{l}\text { Doads } \\ \text { (kW) }\end{array} & \begin{array}{l}\text { Charge } \\ \text { Current } \\ \text { (amp) }\end{array} & \begin{array}{l}\text { Z Crossover } \\ \text { Phase Margin } \\ \text { (degree) }\end{array} \\ 135 & 1.6 & 82 & 62 \\ 135 & 12.5 & 82 & 63 \\ 155 & 1.6 & 72 & 62 \\ 155 & 12.5 & 72 & 63 \\ 180 & 1.6 & 62 & 62 \\ 180 & 12.5 & 62 & 63\end{array}$

\section{CONCLUSION}

The system topology of FESU design has been proposed. The modeling effort has been initiated to make sure that the component level and system level operations are realistic and stable. The primary power system with a BCDU/battery module replaced by FESU is stable for the operating conditions simulated. However, more issues such as fault protection, current sharing, power quality and overall system stability still need to be addressed.

\section{REFERENCES}

1. T. Pieronek, D. Decker, V. Spector, "Spacecraft Flywheel Systems - Benefits and Issues", National Aerospace \& Electronics Conference Proceedings, 1997.

2. P. Li, Model Development, Validation, and Assessment of Battery Charge and Discharge Unit, IA Report C-1691, NASA Johnson Space Center, 1997. 
3. P. Li, "Motion Control Module Analysis," 5th International Workshop on Simulation for European Space Programmes Proceedings, 1998.

4. D. Christopher, R. Beach, "Flywheel Technology Development Program for Aerospace Applications," National Aerospace \& Electronics Conference Proceedings, 1997.

5. BCDU Specification. RC1807 Rev. L, Feb. 7, 1997.
6. L. Dixon, "Average Current Mode Control of Switching Power Supplies." Unitrode Application Note U-140.

7. E. Gholdston, K Karimi, F. Lee. J. Rajagopalan, Y. Panov, B. Manners, "Stability of Large DC Power Systems Using Switching Converters, with Application to the International Space Station," EKE 0-7803-3547-3-7/16, 1996.

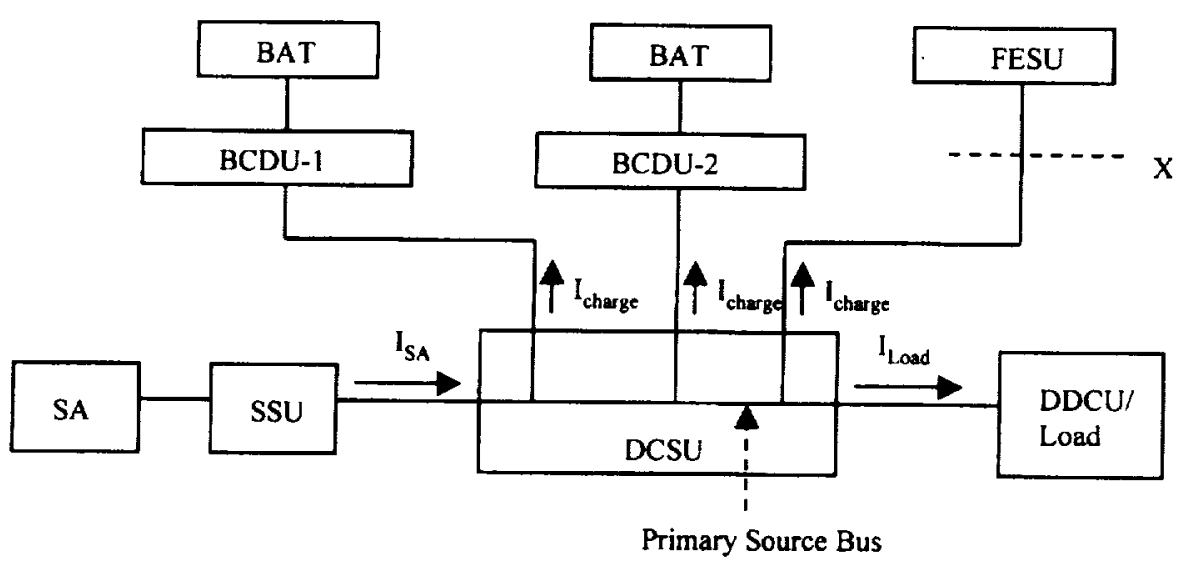

Figure 1: PV System Overview.

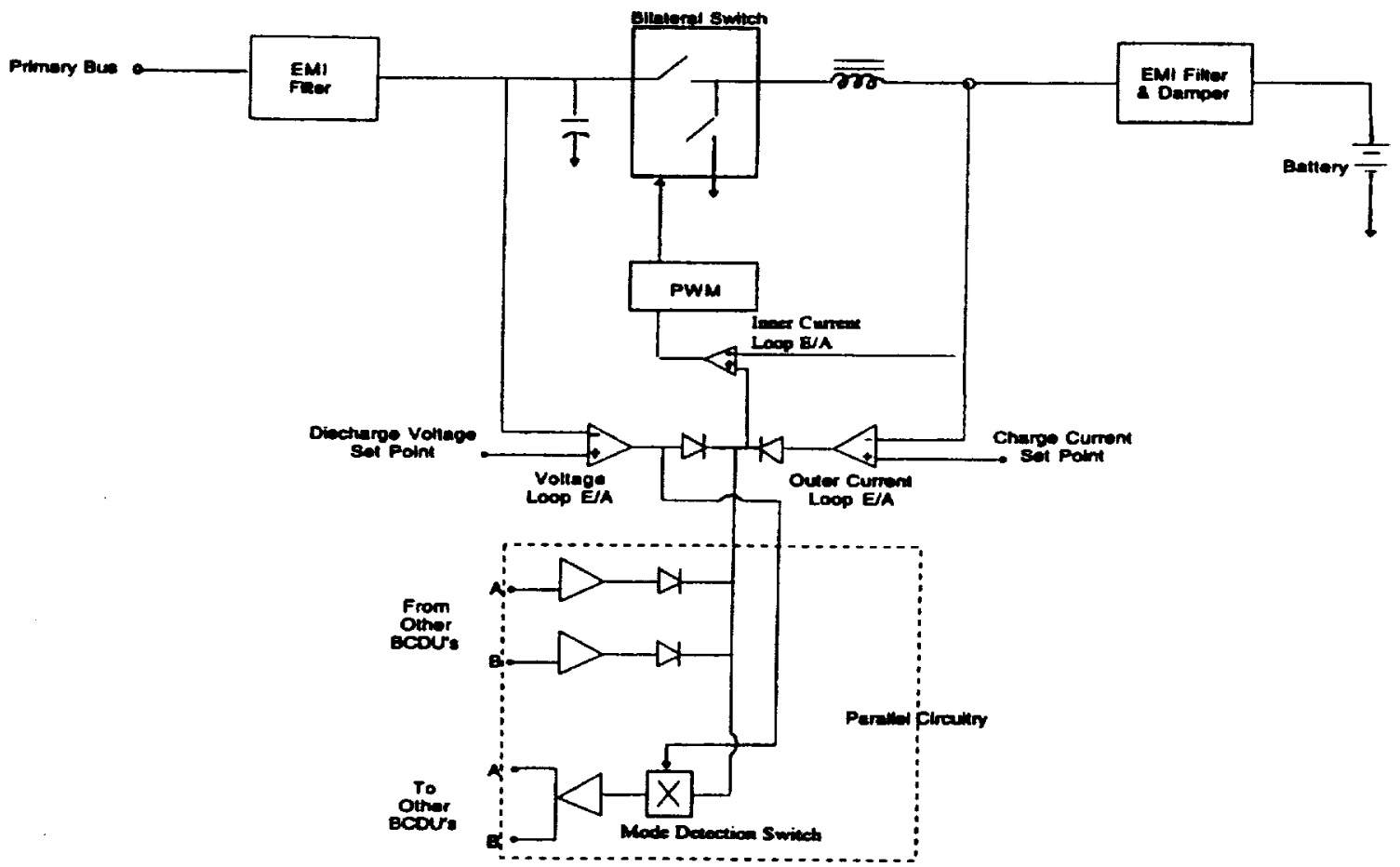

Figure 2: BCDU Fuctional Diagram. 


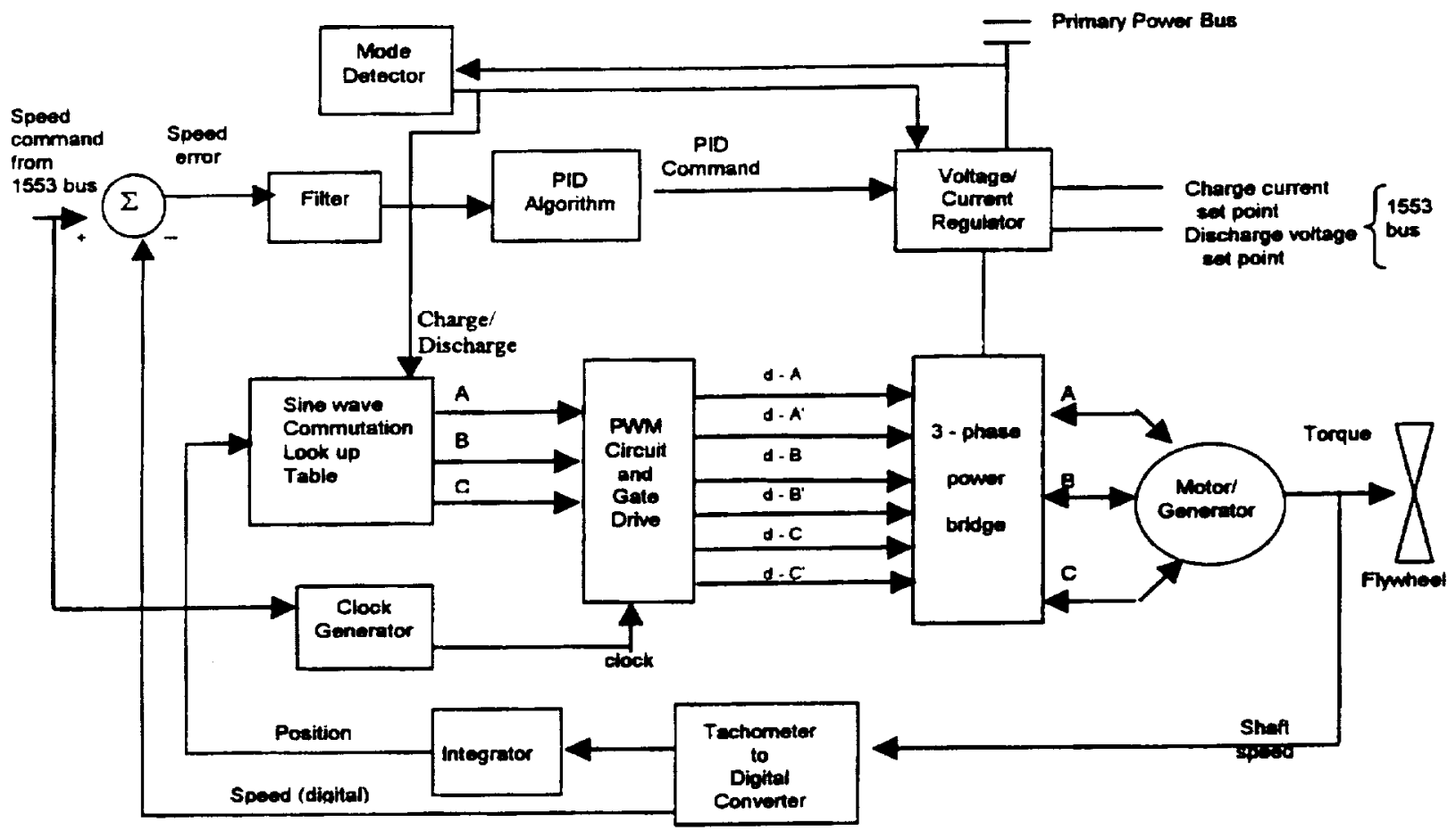

Figure 3: FESU Block Diagram.

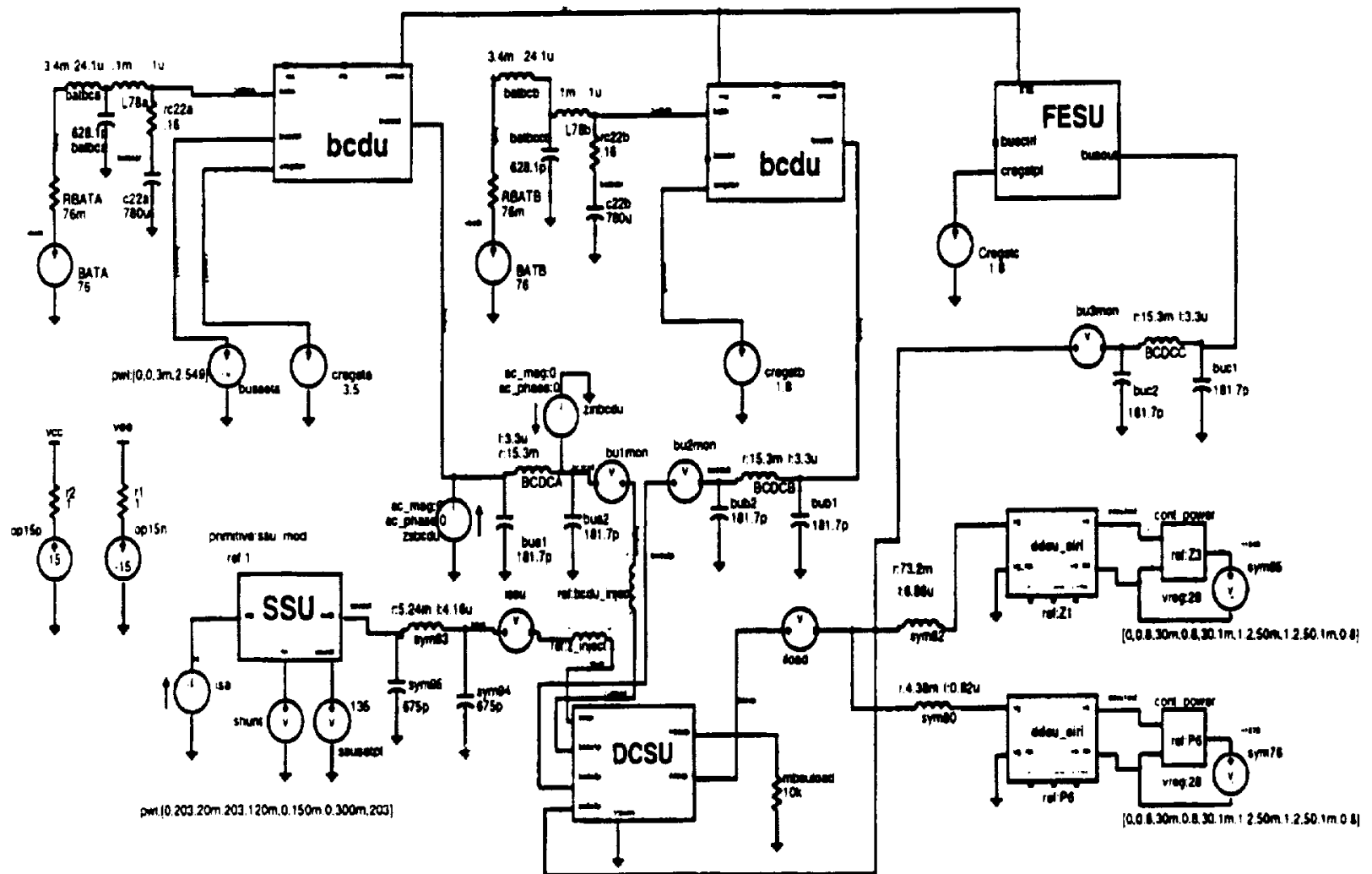

Figure 4: ISS Primary System. 

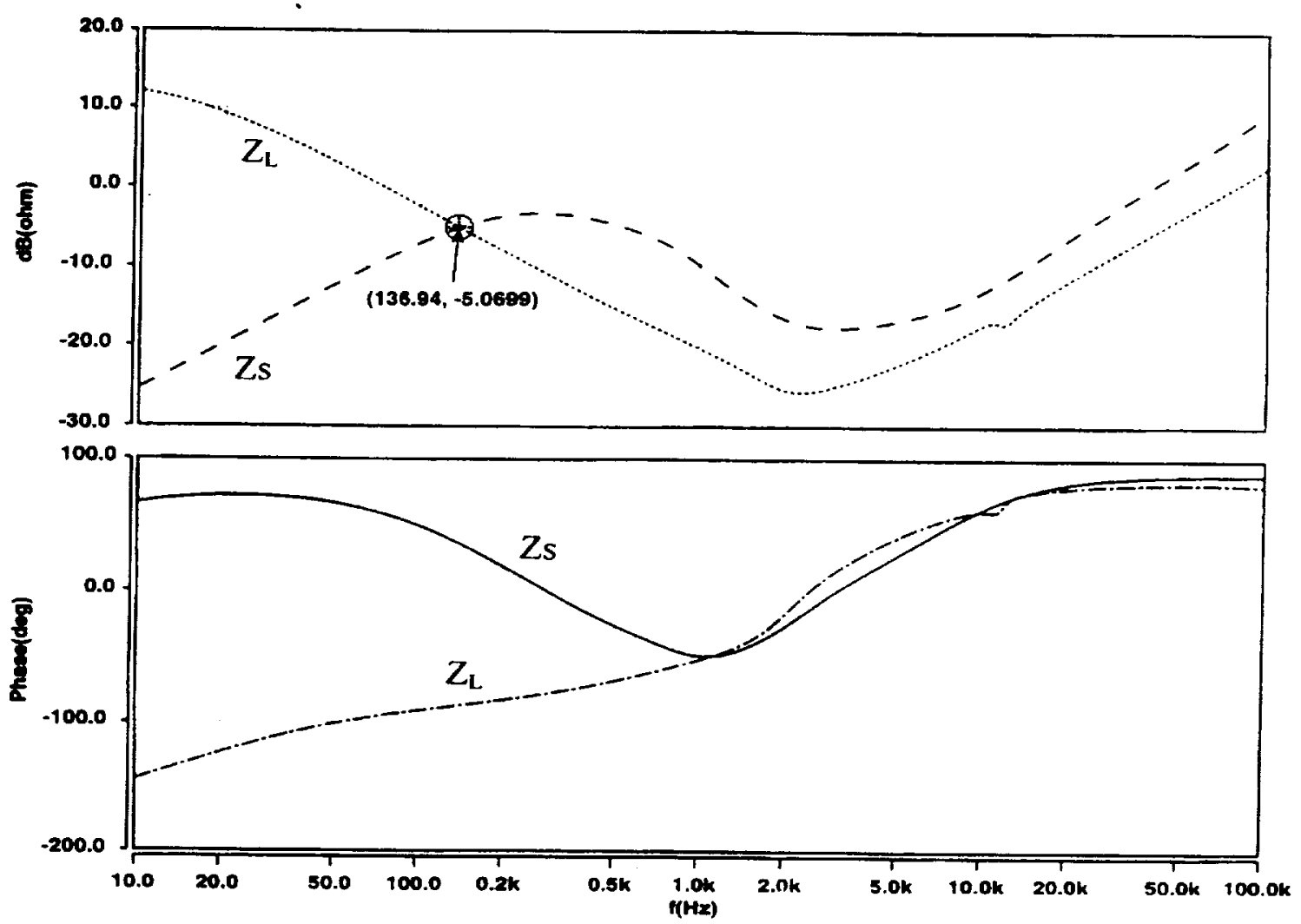

Figure 5: FESU Input/Output Impedance.

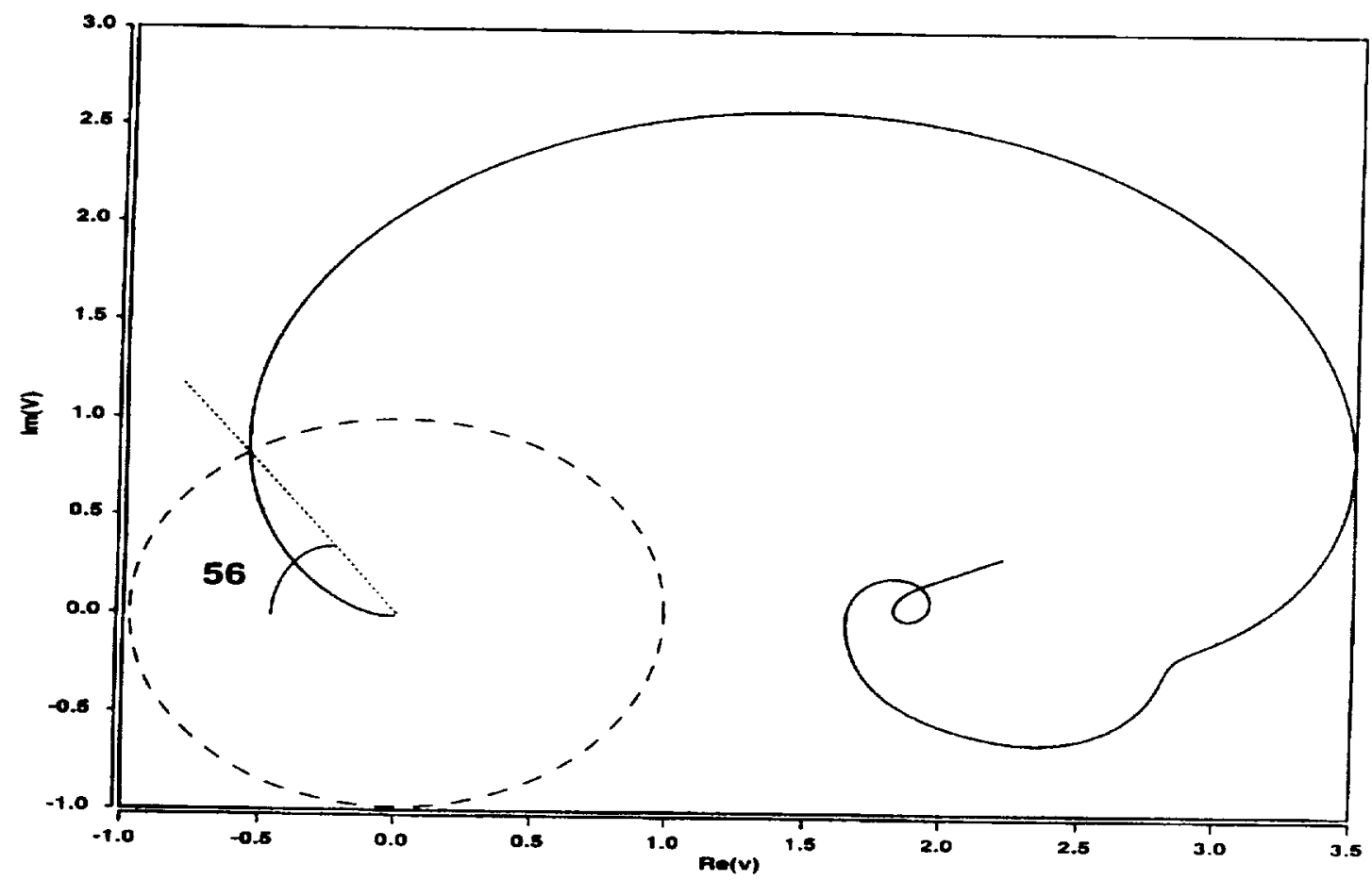

Figure 6: FESU Input/Output Impedance, Nyquist Plot. 



\begin{tabular}{|c|c|c|c|}
\hline \multicolumn{3}{|c|}{ REPORT DOCUMENTATION PAGE } & $\begin{array}{l}\text { Form Approved } \\
\text { OMB No. } 0704-0188\end{array}$ \\
\hline \multicolumn{4}{|c|}{ 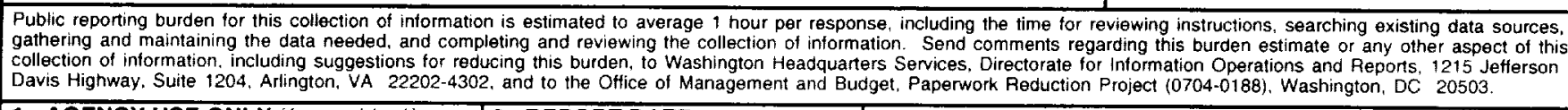 } \\
\hline 1. AGENCY USE ONLY (Leave blank) & $\begin{array}{r}\text { 2. REPORT DATE } \\
\text { July } 2000 \\
\end{array}$ & 3. RE & $\begin{array}{l}\text { D DATES COVERED } \\
\text { echnical Memorandum }\end{array}$ \\
\hline \multicolumn{4}{|c|}{$\begin{array}{l}\text { Simulation of the Interaction Between Flywheel Energy Storage and Battery } \\
\text { Energy Storage on the International Space Station }\end{array}$} \\
\hline \multicolumn{3}{|c|}{$\begin{array}{l}\text { 6. AUTHOR(S) } \\
\text { Long V. Truong, Frederic J. Wolff, Naravan V Dravid and Ponlee Li }\end{array}$} & WU-494-21-11-00 \\
\hline $\begin{array}{l}\text { 7. PERFORMING ORGANIZATION NAI } \\
\text { National Aeronautics and Sp } \\
\text { John H. Glenn Research Cen } \\
\text { Cleveland, Ohio } 44135-319\end{array}$ & $\begin{array}{l}\text { AND ADDRESS(ES) } \\
\text { Administration } \\
\text { t Lewis Field }\end{array}$ & & $\begin{array}{l}\text { 8. PERFORMING ORGANIZATION } \\
\text { REPORT NUMBER } \\
\text { E- } 12387\end{array}$ \\
\hline $\begin{array}{l}\text { 9. SPONSORINGMONITORING AGEN } \\
\text { National Aeronautics and Spa } \\
\text { Washington, DC 20546-000 }\end{array}$ & $\begin{array}{l}\text { AMME(S) AND ADDRESS } \\
\text { Administration }\end{array}$ & & $\begin{array}{l}\text { 10. SPONSORING/MONITORING } \\
\text { AGENCY REPORT NUMBER } \\
\text { NASA TM-2000-210341 } \\
\text { AIAA-2000-2953 }\end{array}$ \\
\hline
\end{tabular}

Prepared for the 35th Intersociety Energy Conversion Engineering Conference sponsored by the American Institute of Aeronautics and Astronautics, Las Vegas, Nevada, July 24-28, 2000. Long V. Truong, Frederic J. Wolff, and Narayan V. Dravid, NASA Glenn Research Center; and Ponlee Li, MP International, 4320 Stevens Creek Blvd., San Jose, California 95129. Responsible person, Long V. Truong, organization code 5490, (216) 433-6153.

12a. DISTRIBUTION/AVAILABILITY STATEMENT 12b. DISTRIBUTION CODE

Unclassified - Unlimited

Subject Category: 20

Distribution: Nonstandard

This publication is available from the NASA Center for AeroSpace Information, (301) 621-0390.

13. ABSTRACT (Maximum 200 words)

Replacement of one module of the battery charge discharge unit (BCDU) of the International Space Station (ISS) by a flywheel energy storage unit (FESU) is under consideration. Integration of these two dissimilar systems is likely to surface difficulties in areas of system stability and fault protection. Other issues that need to be addressed include flywheel charge and discharge profiles and their effect on the ISS power system as well as filter sizing for power Ability purposes. This paper describes a SABER based simulation to study these issues.

\section{SUBJECT TERMS}

15. NUMBER OF PAGES

Aerospace flywheel energy storage system; Simulations and modeling; Aerospace power

\begin{tabular}{|c|c|c|}
\hline $\begin{array}{c}\text { 17. SECURITY CLASSIFICATION } \\
\text { OF REPORT } \\
\text { Unclassified }\end{array}$ & $\begin{array}{c}\text { 18. SECURITY CLASSIFICATION } \\
\text { OF THIS PAGE } \\
\text { Unclassified }\end{array}$ & $\begin{array}{c}\text { 19. SECURITY CLASSIFICATION } \\
\text { OF ABSTRACT } \\
\text { Unclassified }\end{array}$ \\
\hline
\end{tabular}

NSN 7540-01-280-5500
12

$\mathrm{AO3}$

20. LIMITATION OF ABSTRACT

Standard Form 298 (Rev. 2-89) Prescribed by ANSI Std. 239-18
$298-102$ 

